\title{
Medical Image of the Month: Complexity of Healthcare Payment
}

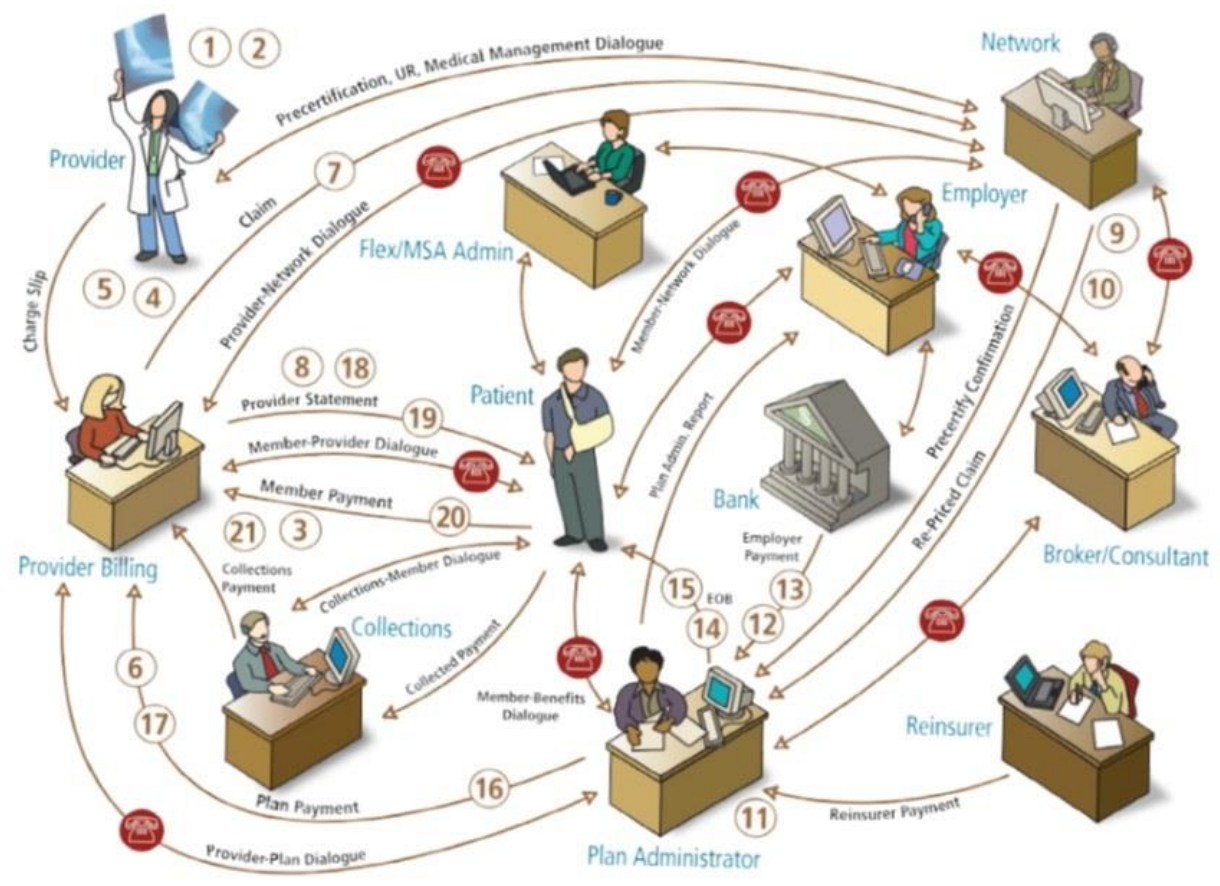

Figure 1. An illustration taken from an advertisement from a company that claims to simplify healthcare payment.

It is generally agreed that healthcare costs are too high in the US. In ground-breaking work published in 1991, Woolhandler and Himmelstein (1) found that US administrative health care costs increased $37 \%$ between 1983 and 1987 . They estimated these costs accounted for nearly a quarter of all health care expenditures. Himmelstein now estimates that administrative costs may now account for up to $40 \%$ of healthcare costs (2). The cartoon shows one provider and one patient but 8 healthcare administrators. This payment system is overly complex involving multiple steps and personnel, with each administrator "dipping their beaks" adding to healthcare costs.

Alp Umar, MD and Richard A. Robbins, MD Arizona Chest and Sleep Medicine Phoenix, AZ USA

\section{References}

1. Woolhandler S, Himmelstein DU. The deteriorating administrative efficiency of the US health care system. N Engl J Med. 1991;324(18):1253-8. [CrossRef] [PubMed]

2. Robbins RA, Natt B. Medical image of the week: Medical administrative growth. Southwest J Pulm Crit Care. 2018;17(1):35. [CrossRef] 